\title{
Mobile Television: Understanding THE TECHNOLOGY AND OPPORTUNITIES
}

\author{
Omar AlSheikSalem ${ }^{1}$, Hazem Qattous ${ }^{2}$ and Mohammad Hijjawi ${ }^{3}$ \\ ${ }^{1}$ Department of Software Engineering, Applied Science Private University, Amman, \\ Jordan \\ ${ }^{2}$ Department of Computer Science, Applied Science Private University, Amman, Jordan \\ ${ }^{3}$ Department of Computer Network Systems, Applied Science Private University, \\ Amman, Jordan
}

\begin{abstract}
Television have converged the technologies of movies and radio and now being converged with mobile phones. Mobile TV is the result of the convergence between mobile devices and television. Mobile TV is a key device and service that enrich civilization with applications, vast market and great investment. Mobile $T V$ is an important subject that has a potential impact on leading edge technologies for promising future. In the time being Mobile TV is still in its early stages and has many potential; therefore some applications such as mobile advertising and learning are discussed in this paper. When it comes to advertising, Mobile $T V$ presents a new opportunity different from the traditional TV advertisements producing an interactive type of advertisements, enabling user engagement. While in the case of mobile learning, mobile devices open up new chances for absorbing knowledge and most recent information without forgetting the practical experience aspect.
\end{abstract}

\section{KEYWORDS}

Convergence, Mobile TV, Customization, Interaction, Mobile Content.

\section{INTRODUCTION TO MOBILE TV}

Mobile TV is the name of the service described to subscribers that is delivered to users through mobile telecommunications networks. Mobile TV is a notable development of the $21^{\text {st }}$ century. It has been clear that Mobile TV has a great potential throughout the improvement cycle and the various range of applications. South Korea is the country at the leading position in Mobile TV sector and British Telecom followed it to be the first company to implement Mobile TV outside of South Korea. This paper mentions some of the failure experiences in the market of Mobile TV; the failure was because of the bad service or the bad timing the service was launched at. Virgin have stopped providing Mobile TV service after six months of its announcement. In addition to that the Dutch operator KPN switched off their DVB-H Mobile TV because of the shortage of mobile devices that support that technology. 


\section{MASS Media, Socialization AND MobiLe Tv}

Communication media comprises the various types of technical methods that assist the communication between the message sender and the message receiver. Mass media is a term used to describe spoken, written or broadcasted communication that reaches a large audience [3]. These messages promote not only products, but attitudes and thoughts. Mass media includes mobile devices, for example Mblogs etc., since media is the intermediary between sender and receiver, most users prefer using TV to gain information. Mobile communication, especially mobile TV, is the synonym for the traditional TV, and TV is one of the main socialising agents of today's society. To prove what was stated about the importance of TV and mobile TV in this research paper, the average high school graduate students in America does spend most of his time in front of the TV even more than what he/she spends in their classrooms at school [2].

Socialisation is the individual's skill in participating within society. Mass media is a powerful socialising mediator. Mass media literally is a way for interacting between people and to learn about the world we are living in. Our knowledge on government is based on mass media information supplied to individuals; we depend on the mass media for what we need to know about the world's politics. Politicians look forward to debating on mass media because it delivers their messages; not only politicians, but also actors and celebrities gain fame from mass media. Media is used as well for people to stay in touch with their friends and relatives [2].

The combination of both information and entertainment, known as infotainment, is driving the world. The different types of communication this paper is concerned with are mobile communications, such as Mobile TV and mobile web. Today, even the poorest people in society own a TV, and have access to at least one type of communication or more, such as TV, radio and internet applied to mobile devices [3]. Mass media using mobile devices should catch people's attention by producing quality material that is worth viewing by users. For Mobile TV, people are supposed to subscribe and pay money to receive Mobile TV, or any other type of mobile communication, but users are flooded with many videos which do not reach the quality standard users are looking for. Content producers are trying to meet consumer requests. Mobile interactive advertisements should be generated to a high quality standard if revenues were the objectives of advertisers and content producers. Quality materials is the key point for generating audiences to the service, which means public attention, financial support, reliability and user interaction to create a new society [1].

\section{MobiLe TV TEChNOLOGIES}

Even though Mobile TV and its services are at present in their infancy in some countries, most predictions seem to be positive concerning growth. Yet, some issues are still vague such as the technologies of Mobile TV.

Around the world many trials are taking place using Mobile broadcast digital TV (DTV). In Korea mobile DTV is being used by a direct link from satellite to phone. Trials underway in selected counties around the world such as Europe, Japan and the U.S. In 2007, it was expected that the infrastructure will be deployed around the world in a robust way [4]. As the use of multimedia has increased the need for a new ways to bring a higher bitrates. Satellite is expected to serve this demand without excluding the power of the terrestrial networks but with it; the researchers has reached a Hybrid Satellite-Terrestrial Cooperative Network and vice versa [5]. 
In addition to that, the third generation (3G) networks of mobile communication offers data transmission speeds ranging from several hundred Kbps to several Mbps depending on the nature of the application. When using fast wireless networks it will become possible to view high-quality audio and video to mobile handsets. As wireless communication is developing rapidly there are many more ways for multimedia content to be transmitted via wireless channels. A research firm eMarketer stated that the Mobile TV service was used by 44.5 million 3G subscribers globally in the year 2006. The report predicts that numbers will double yearly until it reaches 520.9 million by 2009 [21]. The predictions shows that Mobile TV is under increasing demands, which reflected the urgency to improve the mobile services infrastructure That resulted the fourth generation $(4 \mathrm{G})$ technology, which provides the users with a reliable and fast broadband mobile connection. $4 \mathrm{G}$ is expected to offer data transfer at speeds for on the move users with around $100 \mathrm{Mbit} / \mathrm{s}$ while low mobility users will be enjoying around 1Gbit/s [23]. According to the study carried out by GlobalWebIndex, the $4 \mathrm{G}$ technology is booming in the market, as of the first quarter of 2015 almost $1 / 4$ of smartphone users around the world are using 4G network; that is about 500 million 4G users and is expected to reach 2.3 billion by 2018 [14].

\section{Mobile Tv Transmission}

The mainstream of commercial Mobile TV that has been launched worldwide based on a two way cellular networks, with the use of unicast systems. The content of the unicast system is delivered from one source to one destination. And in this situation each users can obtain their preferable content. However, when using broadcast systems a large number of mobile devices gets the same content delivered in a single transmission. The nomadic use of fixed computing devices with the existence of $(3 \mathrm{G})$ and universal mobile telecommunications system (UMTS) mobile phones, offers interactive TV on the go [20].

Network capacity and investments can be improved when using a combination of unicast and broadcast. The most popular programs are using broadcast carriers and using unicast it can deliver an on demand and unrestricted number of additional programs. It is not recognizable to the viewer how content is transmitted when using the combined unicast-broadcast scenario. For the users to have access to all the content they should have a TV client. Using the combination of broadcast and unicast, people get the optimal method for meeting customization and mass market.

\section{MOBILE TV STANDARDS}

A variety of standards of Mobile DTV broadcast have been accepted around the world. The open and non-proprietary will be clear standard winners. When standards are open, they allow for creating markets with wider applications, services development and allow better interoperability between devices. Therefore, users will be able to create the proper mix of services that fulfill their needs. Such as all of the new technologies around the world, there are various mobile DTV standards around the globe. Below you will find most primary open standards regarding the MDTV marketplace.

- DVB-H (digital video broadcast - handheld) is adopted in many countries such as the U.S., Australia, parts of Europe and some Asian countries.

- ISDB-T (integrated services digital broadcast - terrestrial) considered to be the standard in Japan.

- DMB (digital media broadcast) is being used in Korea these days along with numerous devices available in-the market to back up the typical. It has also started to expand in Europe and more parts of Asia 


\section{Market Projection Of Mobile Tv}

This paper argues that Mobile TV as a service will boom due to the fact that infrastructure, handsets, and users are ready for the viewing experience. As it is presented by eMarketer on the worldwide usage of mobile devices, customers around the world are adopting mobile devices extremely fast [7]. Moreover, it is expected that by the end of 2014, 1.76 billion people will be owning and using smartphones in a monthly basis, which is $25 \%$ more than the year before [7].

In the year 2014 almost one quarter of the world's population will be using smartphones [7]. But by the year 2017, the number of people who will be using smartphones will be almost one third of the world's population [7]. Nonetheless, these estimations are done by eMarketer's based on the people who use and own smartphones, ignoring the fact of how many smartphones each individual owns [7].

eMarketer research does not seem to state that in many countries more than half of the total population do own or will be owning an advanced mobile devices [7]. Monica Peart, senior forecasting analyst at eMarketer stated that by 2015 more than 15 countries is projected to have half of their total population of those who own smartphones [7]. This will have an impact on the consuming media, ecommerce, and marketing. In addition to that, users are ready for the viewing experience. According to Nielsen's Q1 2014 Cross-Platform report, the increase in monthly time spent by users for mobile video by twenty six minutes when they have compared the first quarter of 2013 to the first quarter of 2014 [22].

\section{MobiLe Tv Content}

The Mobile TV viewing experience must have a different video content that is to match the particularity of mobile devices, therefore the new programme formats are classified into: Closeups and talking heads; Mobisodes; Snackable; Visual sceptical and much more types [6].

When talking about the most popular content that users will be watching it is worth mentioning the following: News headlines, movies, music video clips, entertainment, children's programs, and sport. The content will be tailored for mobile devices taking into consideration its specifications; therefore user generated content is important, short videos (Mobisodes), interactivity and taking all distribution formats into consideration [6].

In this paper this is not the case; both tailored and ordinary content should be provided as mobile devices specifications are changing and with the availability of wearable devices both content will be acceptable. The Mobile TV customization allows users and broadcasters to be close, and in the marketing case it offers a way to communicate between the users and the service providers. Many advantages to all of the stakeholders can result from such communication. For example targeted content, personalized advertising and new content formats. Users will start to utilize the clickthrough opportunities enabled by Mobile TV which will develop a new behaviours based on personalisation.

Providing TV shows that suites numerous screen sizes was a target from many stakeholders. Supplying Mobile TV users with a fast paced customized programmes. Such programmes can suite many contexts, such as delivering TV programmes to users while transporting from a place to another. Therefore such a programmes should emphasis the meaning of brevity by being no more than three minutes of length which strengthens the idea of brevity and about the words, interactivity and user-generated content agrees with the word spontaneity, with popular content expected to be dominated by personalization, interactivity and user-generated content. 
Mobile TV content types could be either tailored content or ordinary content and the figure below reflects these two types.

\section{Video Content}

\section{Tailored Content}

\section{Ordinary Content}
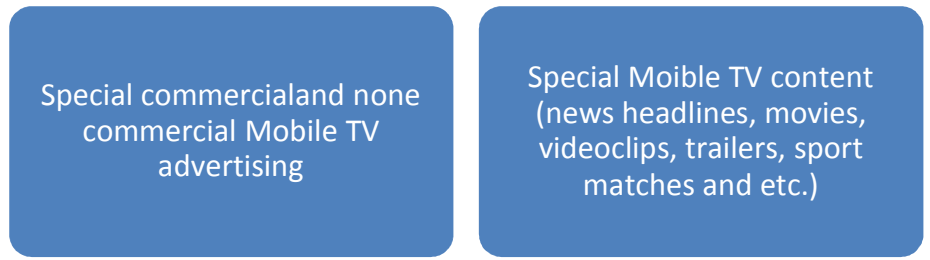

Video content displayed on

traditional TV ranging from

(videoclips, advertisements,

movies, news headlines,

sportmatches, trailers and etc.)

Figure 1. Mobile TV types of content

The developing Mobile TV has been classified according to the content. Below are the three main categories:

- Offline Mobile TV: Offline Mobile TV: which correlates to the services between mobile devices and a fixed network that need synchronization in order to download video content which is known as video podcasting,

- Pure Broadcast Mobile TV: a content that is delivered via a broadcast network, forms the service.

- Connected Mobile TV is a service that connects networks with mobile devices in a two way channel. It is called ( 3 or 4 ) G or in the case of wireless is called WiFi or WiMAX.

\section{Mobile TV OpPORTUNities}

In all means Interactivity is the key that will be the moving Mobile TV services. Many people will argue that this will enable users to become more proactive or passive video or Television viewers which will lead to a less call traffic. On the other hand broadcasters and service providers will benefit from the mobile market as having a well-defined service with many applications and a way to generate money with an ability for a billing service. Mobile TV business model could be classified into a Free Mobile TV service, Premium Mobile TV service, and Licensed Mobile TV service.

As the infrastructure is available then users will be encouraged to use services such as Mobile TV, Mobile purchasing, Mobile voting, Mobile learning, Mobile health, and etc. For instance the education sector could use Mobile TV for training and learning with advertisers opening a new opportunity for them. More revenue will be gained by mobile operators, and the media sector can provide specially tailored video for mobile TV, organizations that get success in the market through advertising on Mobile TV, and the whole population for entertainment. 


\section{Mobile AdVertising}

Mobile marketing is prosperous and its showing in numbers since the revenue is increasing dramatically. People acknowledge its importance and that it has opened opportunities for marketers to reach consumers personally. On the other hand some parties don not agree on the effectiveness of mobile marketing. This paper emphasises on the importance of mobile marketing since there are profit numbers that show the opposite. In addition to that, Because of the fragmentation that occurred to mass markets, untargeted mass communication, particularly advertising on media, became less effective whereas targeted advertising has become the dominant factor [16] [17] [18].

A discussion on the mobile marketing development is stated by Leppäniemi et al. [15] who have observed from the review of Mobile Marketing they have carried out that marketing communications in mobile media is seen as: Mobile Marketing and Advertising, Wireless Marketing and Advertising. They had 21 definitions of marketing communication in mobile media. Mobile Marketing Association ([19], p. 22) defines mobile marketing as "the use of wireless media as an integrated content delivery and direct-response vehicle within a cross-media marketing communications program." In this paper our notes will be concerning mobile advertising so it's defined as a form of advertising via mobile (wireless) handsets. It is a subset of mobile marketing.

The philosophy behind the advertising industry is likely to change from one that is about getting as many eyeballs on the advert as possible to getting people to actually want to see the advert. Since mobile devices are something that people carry with them all the time, and are connected to the wider world around them, they are the perfect delivery mechanism -- so long as the adverts are requested by the end user.

Regarding advertising, traditional television is no more a dependable way to reach the viewers because of the decreasing number of TV viewers so the 30 second advert no longer satisfies the advertisers. So there should be some new channels to and ways to attract the consumer's eyeballs by vendors and advertisers. The vice president of Ericsson Mobility World, Kurt Sillen, says:" Customised mobile advertising adds value to existing mobile TV services." [13]

The domain of advertising is moving towards channels that are digital, to reach the lots of users this is a reason for why users have shifted to the digital interactive devices. A problem with a decline in revenues from traditional TV advertisements leads to an alert to mobile content producers in investigating a new revenue generation models.

Mobile TV advertising sends Catch-up snap videos to the viewers of stations on Mobile TV. Advantages include keeping people up-to-date with new offers and products, and creating a response and the opportunity to grow the number of consumers. Added to that if producers increase loyalty of consumers, then consumers will have free Mobile TV channels from the revenue of adverts [8].

Engaging viewers directly with mobile video adverting is the optimal way of making them excited and that could be through a video which is exciting and stimulates a reaction. Google's chairman/CEO Eric Schmidt said that "any future development would involve internet-based TV", in addition to that companies should deliver a better metric approach than what the existing broadcasted TV advertising provides[9].

Advertisers are looking to mobile devices as users seeks out for free TV. A study shows that advertising on mobile devices is predicted to expand through the upcoming five years, which will create a market that values more than $\$ 11.3$ billion ( $£ 6$ billion) per year [10], by convincing consumers to accept it by offering a content which is free. "People likes something that provides a benefit such as access to content, things like sponsorship, branded content, giving stuff away like Coca-Cola gave away songs on iTunes," Smith said[11]. 


\section{MobiLe TV LEARNING}

As it's obvious to everybody the entire world is going mobile. Mobile devices such as phones, PDA's and etc. these devices which are pocket size and can be used to link people to a virtual informational world through the world wide web, adding to that the main cause of developing these devices which is to contact people by calls. The bullet point here is that users can be contacted anytime anywhere and moving from this bullet point new applications is going to be applied to these devices. An application such as mobile learning is very useful in teaching children because mobile devices are interactive and distributed one to each student.

While many young children do hate studying and schools, the trend of teaching should change through including preferable ways by these kids. The new innovated way is m-learning or mobile learning, teaching using mobile devices which can enrich the educational sector. These young students are related to the new technologies such as mobile devices, people who are responsible of the educational sector must take advantage of this relation to improve the sector.

Mobile technologies have spread extremely fast during the last period of time and featured as anytime anywhere device, these devices are rich with interactivity which supports teaching and learning. Mobile technologies will have a great impact on learning, so learning is moving from just having to study in a classroom to study wherever students are, building a whole environment interested in learning and gaining knowledge with a personal intention or motivation. The future work will be shifting from the 'must' studying to the 'want' studying using mobile technologies in order to study at any time of the day.

Two learning systems on mobile devices have been applied and tested in the year 2003 [12], this course uses SMS messages which is sent to students containing vocabulary acts as a reminders to be revised. These SMS were proven to be effective and well adapted by students. Researchers had noted that even students do postpone their studies until they find spare time to concentrate on their homework [12]. Digital video delivered on mobile phones and PDAs were used to demonstrate the special use and the exact meaning of English idioms. Students said that they didn't like the video because the quality was low but the experience itself is great [12]. The other commercial application is the English-Japanese, Japanese-English dictionary Pocket Eijiro 1, which was deployed in December 2002, proved that it succeeded according to the numbers in which exceeds 100,000 of received hits a day on the site and the number of subscribers that exceeded hundreds of thousands [12].

\section{CONCLUSIONS}

Media convergence is a group of various products that are joint together to make one product which includes the advantages accumulated from all of the products, also known as 'black box'. Mobile convergence and rich media are thought to be very important requirements for the evolution of Mobile TV service.

There are lots of people whom are not enthusiast about Mobile TV and the reasons behind that are the problems of the contents and how TV do work but they will be encouraged by fixing these problems. Currently, the infrastructure of Mobile TV is available and mobile phones can accept all types of media.

This research paper is important in many fields; such as mobile advertising and mobile learning. If you tried to watch TV you can watch what you want by changing channels until the desired content is found, and if the channel has the content which you are looking for it's not in the time which suits you. It is difficult to choose by the popularity of the programme and it is about what the editor thinks is important, and TV shows are beyond reality often including fake public or 
content dependent on the propaganda followed by the editors, therefore TV in its existing state is wonderland reality. Lots of people these days would prefer to watch TV without that much of untargeted adverts because it does make them uncomfortable watching the program. Therefore th need for a new type of content to be displayed on mobile devices is acquired. Mobile TV is the Blackhorse in which many stakeholders can benefit from. Mobile TV content can vary from ordinary TV content to a special tailored content that suites the different viewing experience on Mobile TV when compared to traditional TV.

\section{ACKNOWLEDGMENT}

The authors are grateful to the Applied Science Private University, Amman, Jordan, for the full financial support granted to this research.

\section{REFERENCES}

[1] Khouri, R., The Role and Power of the Mass Media, Passia Seminar 1999 Media and Communication Skills [Online] Available: http://www.passia.org/seminars/99/media_and_communication/rami2.html.

[2] MASS MEDIA \& SOCIETY, A Sociological Perspective on Media, Resources Consulted: Alexander, Alison and Jarice Hanson. 1999. Taking Sides. Mass Media and Society. CT: Dushkin/McGraw-Hill. Croteau, David and William Hoynes. 2000. Media/Society. Industries, Images, and Audiences. Thousand Oaks, CA: Pine Forge Press. Graber, Doris. 1980. Mass Media and American Politics. Washington, DC: Congressional Quarterly Press. Renzetti, Claire M. and Daniel J. Curran. 1998. Living Sociology. MA: Allyn \& Bacon [Online] Available: http://www.public.asu.edu/ zeyno217/365/notes1.html.

[3] CliffsNotes.com, The Role and Influence of Mass Media, 10 Jan 2009 [Online] Available: http://www.cliffsnotes.com/WileyCDA/CliffsReviewTopic/The-Role-and-Influence-of-MassMedia.topicArticleId-26957, article Id-26946.html.

[4] Arif Iqbal and Kazi M. Ahmed; School of Engineering and Technology, Asian Institute of Technology, Thailand ; A Hybrid Satellite-Terrestrial Cooperative Network over Non Identically Distributed Fading

Channels; JOURNAL OF COMMUNICATIONS, VOL. 6, NO. 7, OCTOBER 2011; pp. 581-589.

[5] http://www.privateline.com/archive/ti_digitaltvforhandsets.pdf ; accessed 25th July 2015, Texas Instruments Incorporated; 2004.

[6] (Averch, B., The future of TV will be personal,http://microvision.blogspot.com/2006/11/nokia-futureof-tv-will-be-personal.html,MVIS BLOG,30/11/06)

[7] Worldwide Smartphone Usage to Grow 25\% in 2014; June 11, 2014; http://www.emarketer.com/Article/Worldwide-Smartphone-Usage-Grow-25-2014/1010920

[8] MMS Applications. [Online] Available http://www.dialogue.co.uk/pdf/MMS_brochure.pdf.

[9] Natividad, A., Google Testing Video, Mobile Advertising. [Online] Available http://www.marketingvox.com/archives/2006/05/11/google_testing_video_mobile_advertising/, May 11, 2006.

[10] Wray, R., Advertisers look to mobile phones as users seek free TV. [Online] Available http://business.guardian.co.uk/story/0,,1866293,00.html, The Guardian, Thursday September 7, 2006.

[11] Fitzsimmons, C., Mobile TV ads get thumbs down. [Online] Available http://www.guardian.co.uk/media/2007/aug/16/advertising.digitalmedia, MediaGuardian, Thursday August 16, 2007.

[12] Thornton, $P$ and Houser, C (2004). Using mobile phones in education. Proceedings of the 2nd International Workshop on Wireless and Mobile Technologies in Education. JungLi, Taiwan: IEEE Computer Society, 3-10

[13] World First - Customized Mobile TV Advertising, http://www.3g.co.uk/PR/December06/4025.htm, 6th December, 2006.

[14] Visa, (2015), 1 out of 4 mobile phone users is on a 4G network, Copyright AFP Relaxnews, 2015, [Online] Available at: http://vision.visaeurope.com/1-out-of-4-mobile-phone-users-is-on-a-4gnetwork/.[Accessed 23 Aug 2015].

[15] Leppäniemi M, Sinisalo J and Karjaluoto H. (2006) "A Review of Mobile Marketing Research," International Journal of Mobile Marketing Vol. 1 No. 1, pp. 30-40. 
[16] Shaw M. J., Subramaniam, C., Tan G. W and Welge M. E. (2001) "Knowledge management and data mining for marketing" Decision Support Systems Vol. 31 No. 1, pp. 127-137.

[17] Webster, F. E., Jr. (1992) “The Changing Role of Marketing in the Corporation” Journal of Marketing Vol. 56 No. 4, pp. 1-17.

[18] Peppers, D., Rogers, M. and Dorf B. (1999) "Is Your Company Ready for One-to One Marketing?" Harvard Business Review, January-February, pp. 151-160.

[19] MMA (2006) Glossary. Available at: http://mmaglobal.com/modules/content/index.php?id=6. Accessed 12.1.2007.

[20] TSEKLEVES, E., COSMAS, J., AGGOUN, A. \& LOO, J. (2009). Converged Digital TV Services: The Role of Middleware and Future Directions of Interactive Television. International Journal of Digital Multimedia Broadcasting [Online], Volume 2009. Available: http://74.125.155.132/scholar?q=cache:erIwOUgUvncJ:scholar.google.com/+The+nomadic use+of+fixed+computing+devices+in+addition+to+the+development+of+(UMTS)+and+(3 )+mobile+phones, +offers+interactive+TV+on+the+go+(Tsekleves+et+al,+2009).\&hl=en\&a sdt=0,5 [Accessed 1 May 2011].

[21] Personalised adverts mobile TV. [Online] Available http://news.bbc.co.uk/1/hi/technology/6180509.stm, December 14, 2006.

[22] Nielsen, (2014), Emerging Trends in Mobile and what they mean for your Business, [Online] Available at: http://www.nielsen.com/us/en/insights/news/2014/emerging-trends-in-mobile-and-whatthey-mean-for-your-business.html [Accessed 21 Aug 2015].

[23] C. M. Akujuobi and M. N. O. Sadiku, Introduction of Broadband Communication Systems. London, U.K.: Chapman \& Hall, 2007.

\section{Authors}

Dr. Omar Al Sheik Salem is currently an assistant professor at Applied Science University in Amman, Jordan. Dr. AlSheikSalem holds a Ph.D. degree in Computing from Bradford University, UK. His research interests are in Mobile TV, especially in the context of consumer needs and mobile advertisements, E-commerce, multimedia, Mobile TV content, and new ways of advertising and interactive video.

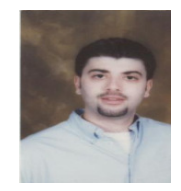

Dr. Hazem Qattous is currently an assistant professor at Applied Science University in Amman, Jordan. Dr. Qattous holds a Ph.D. degree in Computing from Glasgow University, UK. His research interests are in Human-Computer Interaction.

Dr. Mohammad Hijjawi is currently an assistant professor at the Applied Science University in Amman, Jordan. Dr. Hijjawi holds a Ph.D. degree in Computer Science from Manchester Metropolitan University, UK. His research interests include: Conversational Agents, machine learning, Data Mining and Arabic language processing.

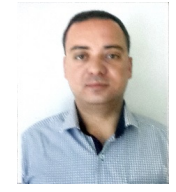

